\title{
Analisis Faktor Teknis dan Non Teknis Keberhasilan Inseminasi Buatan pada Kawasan Sentra Ternak Sapi di Kabupaten Tebo
}

\author{
Fachroerrozi Hoesni ${ }^{1 *}$, Firmansyah ${ }^{1}$ \\ ${ }^{1}$ Faculty of Animal Science, University of Jambi \\ Kampus Pinang Masak Jl. Raya Jambi - Muara Bulian KM.15 Mendalo Jambi \\ ${ }^{*}$ Corresponding Author :rozi.hoesni@gmail.com
}

\begin{abstract}
The success of artificial insemination (IB) in the central area of beef cattle in the Tebo based on technical or non technical indicators are still not satisfactory. To increase the success of the $I B$ to do an analysis of the determinants of the success of the IB in terms of technical factors, as well as non technical factors. The purpose of this research is to analyze the keragaan success rate of IB, and to analyze the effect of technical and non technical factor towards the success of the IB on beef cattle in the central area of Bali cattle in the Tebo. Research methods used in this research is a survey and laboratory techniques, with the withdrawal of sample Cluster Random Sampling that is the central area of beef cattle in the Tebo. The sample size in this study were determined by using the iterati method. Measuring qualitative variables used questionnaire form questions with Scala Likert's Summated Rating's. Validity or kesakhihan research results is determined by measuring instrument which is used i.e. testing the validity of a test (test of validity) and reliability (reliability test of) instruments. The scale of measurement data obtained are ordinal scale that is varied and the ratio. For the ordinal scale of research data done transformation into interval scale using Method of Succesive Interval (MSI). To analyze the effect of the hormone content of inseminator, skills and mineral feed, body condition score and motility of the sperm toward the success rate of artificial insemination in cattle at Tebo Regency in the used path analysis (path analysis).
\end{abstract}

Keywords:

Artificial Insemination, Technical Factors, Cattle

\section{PENDAHULUAN}

Perbibitan adalah kunci utama keberhasilan pencapaian populasi ternak sapi yang diinginkan. Perbibitan ternak sapi perlu ditunjang oleh penerapan teknologi sehingga ternak sapi dapat dioptimalkan potensi reproduksinya. Salah satu teknologi yang telah diterapkan secara massiv adalah Inseminasi Buatan (IB). Penerapan IB memungkinkan pemanfaatan pejantan unggul secara optimal, meningkatkan efisiensi usaha pembibitan ternak sapi pada setiap skala usaha, mempercepat upaya peningkatan mutu genetik ternak sapi, dan menekan penyebaran penyakit-penyakit tertentu pada ternak sapi

Namun berdasarkan hasil evaluasi Kementerian Pertanian Republik Indonesia tentang pelaksanaan Inseminasi buatan (IB) sampai saat ini masih belum sesuai dengan harapan. Hal ini terkait dengan masih adanya berbagai kendala dan permasalahan teknis yang perlu ditangani bersama. Keberhasilan pelaksanaan IB pada ternak sapi telah mencapai 2.116.159 akseptor dengan kelahiran 1.333.075 ekor (Kementerian Pertanian, 2015). Keberhasilan pelaksanaan IB pada ternak sapi di Kabupaten Tebo menurut Laporan Dinas Peternakan Kabupaten Tebo tahun 2016 berbeda-beda (target dan realisasi) di kawasan sentra ternak sapi.

Keberhasilan IB di Kabupaten Tebo berdasarkan indikator teknis masih belum memuaskan. Selain itu kondisi sosial peternak dan petugas atau inseminator juga perlu diperhatikan untuk mencapai keberhasilan IB di Kabupaten Tebo. Untuk meningkatkan keberhasilan IB tersebut perlu dilakukan analisis faktor-faktor penentu keberhasilan IB.

\section{METODE PENELITIAN}

Metode penelitian yang digunakan pada penelitian ini adalah survei dan laboratorium. Ternak sapi Bali yang diinseminasi oleh inseminator pada kawasan sentra ternak sapi di Kabupaten Tebo adalah populasi penelitian ini. Penelitian ini menggunakan tehnik penarikan sampel Cluster Random Sampling. Ukuran sampel dalam penelitian ini ditentukan dengan menggunakan metoda iterati (Harun Al Rasyid, 1994). Langkah pertama untuk memperoleh sampel, terlebih dahulu dihitung total ukuran sampel yang akan diambil melalui :

Pada iterasi pertama digunakan rumus :

$$
n=\frac{\left(Z_{1-\alpha}+Z_{1-\beta}\right)^{2}}{\left(U_{p}^{\prime}\right)^{2}}+3
$$

Keterangan :

$\mathrm{Z}_{1-\alpha}=$ konstanta yang diperoleh dari tabel distribusi normal

$\mathrm{Z}_{1-\beta}=$ konstanta yang diperoleh dari tabel distribusi normal

$\alpha=$ kekeliruan tipe I, yaitu menerima hipotesis yang seharusnya ditolak

$\beta=$ kekeliruan tipe II, yaitu menolak hipotesis yang seharusnya diterima 
$\rho \quad=$ perkiraan harga koefisien korelasi

Uji validitas instrumen dalam penelitian ini dilakukan dengan mengkorelasikan skor masingmasing pertanyaan dengan skor total pertanyaan untuk setiap variabel. Secara umum perumusan nilai korelasi Pearson (product moment pearson) adalah :

$$
r=\frac{n \sum X Y-\left(\sum X\right)\left(\sum X\right)}{\sqrt{\left\{n \sum X^{2}-\left(\sum X\right)^{2} \int n \sum Y^{2}-\left(\sum Y\right)^{2}\right\}}}
$$

Keterangan :

$R=$ Korelasi Pearson

$X=$ Skor pertanyaan

$Y=$ Skor total pertanyaan

$n=$ Jumlah pertanyaan

Selanjutnya untuk signifikansinya diuji dengan formula sebagai berikut :

$$
t_{\text {hitung }}=\frac{r \sqrt{n-2}}{\sqrt{1-r^{2}}} \text { pada } \mathrm{db}=\mathrm{n}-2
$$

Uji reliabilitas instrumen dimaksudkan untuk mengetahui apakah alat pengumpul data pada dasarnya menunjukkan tingkat kepekaan, keakuratan, kestabilan atau konsistensi alat tersebut dalam mengungkapkan gejala tertentu dari sekelompok individu, walaupun dilakukan pada waktu yang berbeda. Uji reliabilitas instrumen pada pelaksanaannya menggunakan metode belah dua (split half method).

Skala pengukuran dari data yang diperoleh adalah bervariasi yaitu skala ordinal dan rasio. Untuk data penelitian yang skala ordinal dilakukan transformasi menjadi skala interval dengan menggunakan Method of Succesive Interval (MSI) yaitu dengan langkah sebagai berikut (Sutawidjaya, 2000).

Model struktural analisis jalur yaitu :

$Y_{i}=\rho_{Y i X 1} X_{1}+\rho Y_{i X 2} X_{2}+\rho Y_{i X} X_{3}+\rho Y_{i X} X_{4}+\rho Y_{i X}$

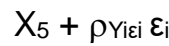

Keterangan :

$\mathrm{Y}=$ Keberhasilan IB

$\mathrm{X}_{1}=$ Motilitas Sperma (Teknis)

$\mathrm{X}_{2}=$ Pengetahuan Peternak (Non Teknis)

$\mathrm{X}_{3}=$ Skor Kondisi Tubuh Ternak (Teknis)

$\mathrm{X}_{4}=$ Ketrampilan Inseminator (Non Teknis)

$\mathrm{X}_{5}=$ Kandungan Mineral Pakan (Teknis)

YYiX $1-5^{-}=$Koefisien Jalur

$\varepsilon=$ Variabel residu

\section{HASIL DAN PEMBAHASAN \\ Faktor Teknis \\ Semen}

Hasil uji semen beku (straw) di tingkat inseminator diperoleh persentase motilitas spermatozoa pada semen ternak sapi di kawasan sentra ternak sapi Kabupaten Tebo yaitu rata-rata sebesar 38,52 \% $\pm 2,28$. Standar Nasional Indonesia (SNI) menyebutkan bahwa konsentrasi spermatozoa sebanyak 25 juta dengan motilitas $40 \%$ dan abnormalitas $<20 \%$. Hasil penelitian Rosita dkk (2013), jumlah spermatozoa motil setelah proses thawing di laboratorium sebesar $30-40 \%$, dan mengalami penurunan proses thawing di lapang sebesar 25 - 40\%. Hal ini disebabkan karena kerusakan pada straw yang berupa perenggangan pada filling-sealing sehingga nitrogen cair merembes dan masuk ke dalam straw dan mengakibatkan

\begin{tabular}{|c|c|c|}
\hline No & Kawasan Sentra Ternak Sapi & Motilitas Spermatozoa (\%) \\
\hline 1 & Dataran Sedang (Kabupaten Tebo) & $38,52 \pm 2,28^{b}$ \\
\hline & Provinsi Jambi & $37,90 \pm 2,49$ \\
\hline
\end{tabular}
spermatozoa mati.

\section{Body Condition Score (BCS)}

Faktor ternak sapi pada penelitian ini dilihat dari skor kondisi tubuh (SKT) yaitu cadangan energi tubuh dapat dinilai dengan metode penilaian visual yang dikenal sebagai body condition score (BCS). SKT adalah metode untuk memberi nilai kondisi tubuh ternak baik secara visual maupun dengan perabaan pada timbunan lemak tubuh dibawah kulit sekitar pangkal ekor, tulang punggung dan pinggul. SKT digunakan untuk mengevaluasi manajemen pemberian pakan, menilai status kesehatan individu ternak dan membangun kondisi ternak pada waktu manajemen ternak yang rutin.

\begin{tabular}{|c|c|c|}
\hline No & Kawasan Sentra Ternak Sapi & Skor Kondisi Tubuh Ternak Sapi \\
\hline 1 & Dataran Sedang (Kabupaten Tebo) & $4,00 \pm 0,37^{b}$ \\
\hline & Provinsi Jambi & $3,55 \pm 0,55$ \\
\hline
\end{tabular}

Tabel 2. Skor Kondisi Tubuh Ternak Sapi di Kawasan Sentra Ternak Sapi Kabupaten Tebo

Keterangan : Nilai mean \pm SD dalam satu kolom yang diikuti oleh huruf kecil yang berbeda menunjukkan perbedaan

Faktor Non Tenis Inseminator
Faktor inseminator pada penelitian ini adalah petugas yang telah dididik dan lulus 
dalam latihan ketrampilan khusus untuk melakukan inseminasi buatan serta memiliki Surat Izin Melakukan Inseminasi (SIMI) yang bertugas pada Kawasan Sentra Ternak Sapi di
Provinsi Jambi mencakup pengalaman, pengetahuan, ketrampilan teknis dan manajemen straw.

Tabel 3. Pengalaman, Pengetahuan, Ketrampilan Teknis dan Manajemen Straw Inseminator di Kawasan Sentra Ternak Sapi Kabupaten Tebo

\begin{tabular}{|c|c|c|}
\hline No & Kawasan Sentra Ternak Sapi & $\begin{array}{c}\text { Pengalaman, Pengetahuan, Ketrampilan Teknis \& } \\
\text { Manajemen Straw }\end{array}$ \\
\hline 1 & Dataran Sedang (Kabupaten Tebo) & $25,86 \pm 3,55^{a}$ \\
\hline & Provinsi Jambi & $25,38 \pm 4,60$ \\
\hline
\end{tabular}

Temuan dari penelitian ini tentang pengalaman, pengetahuan, ketrampilan teknis dan manajemen straw inseminator di kawasan sentra ternak sapi Kabupaten Tebo rata-rata sebesar 25,86\% $\%$ 3,55. Menurut Hastuti (2008) inseminator merupakan ujung tombak pelaksanaan IB sekaligus sebagai pihak yang bertanggung jawab terhadap berhasil atau tidaknya program IB di lapangan. Kondisi ini disebabkan pada saat inseminator bertugas berdasarkan Standar Operasional Prosedur (SOP) IB dan telah memiliki Surat Izin Melakukan Inseminasi (SIMI).

\section{Pengetahuan Peternak}

Pada penelitian ini peternak adalah tingkat pengetahuan peternak tentang reproduksi ternak dan kemampuan peternak mendeteksi estrus. Peningkatan pengetahuan dan keterampilan peternak menyangkut management usaha peternakan dapat meningkatkan populasi ternak, salah satunya adalah management reproduksi menyangkut deteksi estrus dan waktu kawin yang tepat (Parera, 2011). Peran peternak dalam menentukan waktu kawin tepat, akan menentukan keberhasilan kebuntingan dalam sekali perkawinan, sebaliknya penentuan waktu kawin yang tidak tepat, maka kebuntingan dapat terjadi dalam dua sampai tiga kali perkawinan. Temuan di lapangan tentang pengetahuan peternak tentang reproduksi ternak sapi di Kawasan Sentra Ternak Sapi Kabupaten Tebo rata-rata sebesar 28,07 \pm 3,23. Sedangkan pengetahuan peternak tentang reproduksi ternak sapi untuk masing-masing daerah Kawasan Sentra Ternak Sapi Provinsi Jambi tersaji pada Tabel berikut ini.

Tabel 4. Pengetahuan Peternak tentang Reproduksi Ternak Sapi di Kawasan Sentra Ternak Sapi Kabupaten Tebo

\begin{tabular}{ccc}
\hline No & Kawasan Sentra Ternak Sapi & Pengetahuan Peternak \\
\hline 1 & Dataran Sedang (Kabupaten Tebo) & $28,07 \pm 3,23$ \\
\hline & Provinsi Jambi & $\mathbf{3 0 , 2 1} \pm \mathbf{4 , 2 1}$ \\
\hline
\end{tabular}

\section{Faktor Dominan Menentukan Keberhasilan IB}

Untuk mengetahui faktor teknis dan non teknis yang menentukan tingkat keberhasilan Inseminasi Buatan (IB) pada ternak sapi di Kawasan Sentra Ternak Sapi Kabupaten Tebo digunakan analisis jalur (path analysis). Analisis jalur dilakukan pada variabel eksogenus yang mempengaruhi secara signifikan kepada variabel endegonus. Analisis jalur dilakukan guna mengetahui besarnya pengaruh masingmasing variabel independen terhadap variabel dependen. Path Analysis digunakan apabila secara teori diyakin berhadapan dengan masalah sebab akibat (Muhidin dan Abdurahman, 2007).

Sebelum dibuat kesimpulan mengenai koefisien jalur, terlebih dahulu harus dilakukan pengujian mengenai keberartian koefisien jalur, baik secara simultan maupun parsial. Uji statistik yang digunakan untuk mengetahui pengaruh motilitas sperma (teknis $=X_{1}$ ), pengetahuan peternak (non teknis $=X_{2}$ ), skor kondisi tubuh ternak (teknis $=X_{3}$ ), ketrampilan inseminator (non teknis $=X_{4}$ ), kandungan mineral pakan (teknis $=X_{5}$ ) secara simultan terhadap keberhasilan IB pada ternak sapi di kawasan sentra ternak sapi Kabupaten Tebo adalah uji $\mathrm{F}$ (F-test).

Untuk menguji keberartian koefisien jalur secara simultan, maka pasangan hipotesis dirumuskan adalah $: \mathrm{H}_{0}: \mathrm{P}_{Y X 1}=\mathrm{P}_{Y X 2}=\mathrm{P}_{Y X 3}=$ $\mathrm{P}_{Y X 4}=\mathrm{P}_{Y X 5}=0$ dan $\quad \mathrm{H}_{1}$ sekurang-kurangnya ada sebuah $P_{Y X i \neq} 0$. Hasil analisis uji $F$ diperoleh nilai $\quad F_{\text {hitung }}=45,523$ dengan significant $=0,000$ yang berarti hipotesis nol ditolak dan hipotesis alternatif diterima, artinya sekurang-kurangnya terdapat satu nilai koefisien jalur yang berarti (signifikan). Hasil ini menunjukkan bahwa motilitas sperma (teknis $=X_{1}$ ), pengetahuan peternak (non teknis $=X_{2}$ ), skor kondisi tubuh ternak (teknis $=X_{3}$ ), ketrampilan inseminator (non teknis $=X_{4}$ ), kandungan mineral pakan (teknis $=X_{5}$ ) secara simultan mempengaruhi keberhasilan IB pada ternak sapi di kawasan sentra ternak sapi Kabupaten Tebo. Oleh karena hasil pengujian secara simultan (uji F) adalah signifikan, maka selanjutnya dilakukan pengujian secara parsial (uji t). 
Berdasarkan uji t diperoleh hasil untuk kelima jalur yang ada $\left(X_{1}, X_{2}, X_{3}, X_{4}\right.$ dan $\left.X_{5}\right)$, ternyata satu jalur yang tidak signifikan yaitu koefisien jalur untuk pengetahuan peternak (non teknis $=X_{2}$ ) sedangkan empat jalur lainnya adalah signifikan. Adanya koefisien jalur yang tidak signifikan berarti menunjukkan bahwa koefisien jalur tersebut tidak berarti. Hal ini berarti bahwa motilitas sperma (teknis $=X_{1}$ ), skor kondisi tubuh ternak (teknis $=X_{3}$ ), ketrampilan inseminator (non teknis $=X_{4}$ ), kandungan mineral pakan (teknis $=X_{5}$ ) berpengaruh terhadap keberhasilan IB pada ternak sapi di kawasan sentra ternak sapi Kabupaten Tebo.

Kondisi ini sesuai pendapat Correa dkk., (1996), keberhasilan program IB dipengaruhi oleh beberapa hal antara lain: ternak betina itu sendiri, ketrampilan inseminator dalam mendeposisikan semen, ketepatan waktu IB, deteksi berahi, handling semen dan kualitas semen terutama motilitas pasca thawing atau post thawing motility (PTM). Ditambahkan oleh Hastuti (2008), tingkat keberhasilan IB sangat dipengaruhi oleh empat faktor yang saling berhubungan dan tidak dapat dipisahkan satu dengan lainnya yaitu pemilihan sapi akseptor, pengujian kualitas semen, akurasi deteksi birahi oleh para peternak dan ketrampilan inseminator.

\section{DAFTAR PUSTAKA}

Alexander, P. A. B. D., H. Abeygunawardena, B. M. H. O. Perera and I. S Abeygunawardena. 1997. Current Status and Factor Affecting the Success of Artificial Insemination in Small - Holder Farm in the Mid Country Wet Zone of Sri Lanlea. Tripocal Agric. Research. Vol 9. p : 204-206.

Anzar, M. U., Faroq., M. A., Mirza., M. Shahab and N. Ahmad. 2003. Factors Affecting The Efficiency of Artificial Insemination in Cattle and Buffalo in Punjab. Pakistan. Animals Sciences Institute. National Agricultural Research Center, Islamabad Sciences 45500 Pakistan. Departement of Biological Sciences, Quaid - i - Azam University Islamabad 45500 Pakistan. Journal Pakistan Vet. J., 23 (3) : 106 113.

Caraviella, D. Z., K. A. Weigel., P. M. Fricke., M. C. Wiltbank., M. J. Florent., N. B. Cook., K. V. Nordhund., N. R. Zwald and C. L. Rawson. 2006 . Survey of Management Practices on Reproductive Performance of Dairy Cattle on Large us Commercial Farmas. Departement of Dairy Science, University of Wisconsin. Madison 53706. School of Veterinary Medicine, University of Wisconsin, Madison 537. Journal of Dairy Science. 89 (12) : 4723 - 4735.
Carvacho,P.R. 2009. Mineral Imbalances in The Complex Interactions Soil - Plant Animal in The Grasslands of Center West Region of The Sao Paulo State, Brazil. Pakistan J.of Nutrition 8: 1603 - 1612.

Correa, J. R., Rodriquez, Petterson and Zavos. 1996. Thawing And Processing Spermatozoa at Various Temperatures and Their Effects on Sperm Viability, Osmotic Shock and Sperm Membrane Functional Integrity. Theriogenology. Volume 46.

Das, S. S., K. Bandopadhya., S. Basu., B. B. Ghosh and R. Dattagupta. 2009. Blood Mineral Profile of Normal Cyclic and Repeat Breeder Cows Under Rural Condition. Indian Journal of Animals Reproduction 23: 167 - 169.

Harun Al Rasyid. 1994. Teknik Penarikan Sampel dan Penyusunan Skala. disunting oleh Teguh Krismantoroadji dkk., Program Pascasarjana Universitas Padjadjaran, Bandung.

Hastuti. 2008. Tingkat Keberhasilan Inseminasi Buatan Sapi Potong Ditinjau dari Angka Konsepsi dan Service Per Conception. Mediagro. Vol.4. No.1, 2008: Hal : 12- 20

Parera, H., Souhoka, D. F., Serpara, J. E. M. 2011. Kemampuan Peternak Sapi Bali di Kecamatan Teon Nila Serua dalam Mendeteksi Estrus dan Menentukan Waktu Kawin. Agrinimal, Vol. 1, No. 2, Oktober 2011, Hal. 84-87.

Rosita, E. A., Susilawati, T. dan Wahyuningsih, S. 2013. Keberhasilan IB Menggunakan Semen Beku Hasil Sexing dengan Metode Sedimentasi Putih Telur pada Sapi PO Cross. Jurnal IImu-IImu Peternakan Vol. 24 (1) Hal : 72 - 76

Shebu B. M., Rekwot P. I., Kezi D. M., Bidoli T. D., Oyedokun A. O. 2010. Challenges to Farmers' Participation in Artificial Insemination (Al) Biotechnology in Nigeria: An overview. Journal of Agricultural Extension, Vol. 14 (2) : 123129.

Spitzer, J. C., D. G. Morrison, R. P. Wettemann and L. C. Faulkner. 1995. Reproductive Responses, Calf Birth and Weaning Weight as Affected by Body Condition at Parturition and Postpertum Weight Gain in Primiparous Beef Cows. Journal Animal.sci., 73: 1251-1257.

Zdunczyk, S., Mwaanga, E. S., Tepicht, J. M., Baranski, W., and Janowski, T. 2002. Plasma Progesterone Levels and Clinical Findings in Dairy Cows with Post-Partum Anoestrus. Bull. Vet. Inst. Pulawy, 46, pp. 7986. 